University of New Hampshire

University of New Hampshire Scholars' Repository

3-31-2017

\title{
Preference Organization
}

Danielle M. Pillet-Shore

Department of Communication, University of New Hampshire, dvg4@unh.edu

Follow this and additional works at: https://scholars.unh.edu/comm_facpub

Part of the Discourse and Text Linguistics Commons, Educational Sociology Commons, Elementary

Education Commons, Interpersonal and Small Group Communication Commons, Social Psychology

Commons, and the Social Psychology and Interaction Commons

\section{Comments}

This is a pre-copyedited, author-produced version of an article accepted for publication in The Oxford Research Encyclopedia of Communication following peer review. The version of record:

Pillet-Shore, Danielle. (2017). Preference organization. In Jon Nussbaum (Editor), Oxford Research Encyclopedia of Communication. New York: Oxford University Press, (published online March 31).

is available online at: https://dx.doi.org/10.1093/acrefore/9780190228613.013.132

\section{Recommended Citation}

Pillet-Shore, Danielle. (2017). Preference organization. In Jon Nussbaum (Editor), Oxford Research Encyclopedia of Communication. New York: Oxford University Press, (published online March 31). DOI: 10.1093/acrefore/9780190228613.013.132

This Article is brought to you for free and open access by the Communication at University of New Hampshire Scholars' Repository. It has been accepted for inclusion in Communication Scholarship by an authorized administrator of University of New Hampshire Scholars' Repository. For more information, please contact Scholarly.Communication@unh.edu. 


\title{
PREFERENCE ORGANIZATION
}

\author{
DANIELLE PILLET-SHORE \\ Department of Communication, University of New Hampshire \\ Durham, NH 03824 USA
}

\begin{abstract}
Conversation analytic research on "preference organization" investigates recorded episodes of naturally occurring social interaction to elucidate how people systematically design their actions to either support or undermine social solidarity. This line of work examines public forms of conduct that are highly generalized and institutionalized, not the private desires, subjective feelings or psychological preferences of individuals. This article provides a detailed and accessible overview of classic and contemporary conversation analytic findings about preference, which collectively demonstrate that human interaction is organized to favor actions that promote social affiliation (through face-preservation) at the expense of conflict (resulting from face-threat). While other overviews on this topic exist, the present article is the first to synthesize findings about the preference organization of responding and initiating actions, elucidating key preference principles distilled from over 45 years of conversation analytic work, including the preferences for: (i) recipient design, (ii) contiguity and agreement, (iii) progressivity, (iv) offers over requests, (v) recognition over self-identification, (vi) selfcorrection over other-correction, (vii) self-criticism over other-criticism (avoiding othercriticism), and (viii) other-praise over self-praise (avoiding self-praise).
\end{abstract}

\section{Keywords}

preference organization, conversation analysis, language and social interaction, social solidarity, affiliation, face, sequence-responding actions, sequence-initiating actions, preference principles

Online publication date: March 2017 in Jon Nussbaum (Editor-in-Chief), The Oxford Research Encyclopedia of Communication. Oxford University Press.

http://communication.oxfordre.com/

DOI: 10.1093/acrefore/9780190228613.013.132 


\section{PREFERENCE ORGANIZATION}

Conversation analytic research on "preference organization" investigates recorded episodes of naturally occurring social interaction to elucidate how people systematically design their actions to either support or undermine social solidarity. This line of work examines public forms of conduct that are highly generalized and institutionalized, not the private desires, subjective feelings or psychological preferences of individuals. This article provides a detailed and accessible overview of classic and contemporary conversation analytic findings about preference, which collectively demonstrate that human interaction is organized to favor actions that promote social affiliation (through face-preservation) at the expense of conflict (resulting from facethreat; Heritage, 1984; Schegloff, 2007). While other overviews on this topic exist (e.g., Nishizaka \& Hayano, 2015; Pomerantz \& Heritage, 2013), the present article is the first to synthesize findings about the preference organization of responding and initiating actions, elucidating key preference principles distilled from over 45 years of conversation analytic work.

\section{BACKGROUND}

Understanding preference organization requires first understanding that conversation analysis (CA) is primarily focused upon action sequences: CA examines the ways in which participants' audible utterances (including the prosodic design of talk) and visible body-behaviors (including gestures) accomplish particular social actions due to their positioning within a sequence of interaction (Heritage, 1984:245). Consider Excerpt 1, which shows a sequence involving two participants, Nina and Charles. Charles is Nina's adult nephew, and this sequence occurs about 20-seconds after he 
knocks on the door to Nina's home. As Nina and Charles walk from the door entry area toward the kitchen, Nina produces the utterance at lines 1-2, to which Charles responds at line 3.

Excerpt 1 [Pillet-Shore F15 SB-2 (simplified)]

01 Nina: Do you wantu:m: (a-/uh-) cuppa coffee er

02 somethi[n?

03 Charles: $\quad[\underline{Y} e: a h .=I$ would absolutely lo:ve a cup of coffee.

Rather than focusing on the topic of these participants' utterances (i.e., coffee), conversation analysts prioritize explicating the actions that each participant does through their utterances to mirror the interactional participants' own monitoring of one another's actions in real-time (Schegloff, 2007). Thus, when Nina says, "Do you wantu:m: (a-/uh-) cuppa coffee er somethin?" she is constructing her utterance as a question, using that question as a vehicle for doing the action of offering. Continuing the action sequence that Nina's utterance initiates or sets in motion, Charles responds to Nina's offer by saying, "Ye:ah.=I would absolutely lo:ve a cup of coffee.", which performs the actions of answering her question and enthusiastically accepting her offer. So participants do actions through sequences of interaction - an ordered series of moves between different participants. A sequence is a vehicle for getting some activity (e.g., greeting, introducing, offering, proposing, inviting, requesting, registering, assessing) accomplished (Schegloff, 2007:59). While some actions initiate a sequence (by making some sort of response relevant next), others respond. Much of conversational interaction is organized around this basic unit of sequence construction, the "adjacency pair" (Schegloff, 2007:9; Heritage, 1984:246-247; Schegloff \& Sacks, 1973:296). The adjacency pair structure is a normative framework for actions wherein one participant's recognizable production and completion of a first pair part (FPP) action 
initiates a sequence often by selecting a next speaker who should immediately produce an appropriate, type-fitted second pair part (SPP).

Applying this to Excerpt 1, Nina's utterance at lines 1-2 is a FPP that initiates a sequence by normatively requiring that her addressed-recipient Charles respond immediately - and not just with any kind of response (e.g., "I love you too"), but with a type-fitted SPP. Because Nina's FPP is an offer, it makes relevant next a SPP that either accepts or declines her offer. But these alternative relevant actions are not socially, interactionally symmetrical or equivalent (Heritage, 1984; Schegloff, 2007; Pillet-Shore, 2010; 2011) because each alternative has different implications for "face" (participants' interdependent, public images of self; Goffman, 1967; Brown \& Levinson, 1987; Lerner, 1996) and "affiliation" (participants' continually updated displays of being 'with' or 'against' one another; Sidnell, 2010; cf. Lindstrom \& Sorjonen, 2013), and thus the relationship of the participants involved. Preference organization research empirically investigates the interactional consequences of such alternative actions.

\section{PREFERENCE BASICS: ACTION AND DESIGN}

Many action types - both sequence-initiating and sequence-responding - involve at least two relevant alternatives. As an example of alternative sequence-initiating actions, consider this: when transferring something of value (object, service, information) from one person to another, the person who has the valued transferable may offer it through a FPP (as Nina does in Excerpt 1), or the person who is the potential recipient of the valued transferable may request it through a FPP (Schegloff, 2007:82). And, as examples of alternative sequence-responding actions, consider the 
following: when presented with a FPP offer or invitation, we may accept or decline it; likewise, when encountering a FPP request, we may grant or refuse it; when hearing an assessment, we may agree or disagree with it; and when we perceive a problem with another's talk, we may allow that person to self-correct or we may correct her/him. In CA work, these alternatives have been connected to Brown \& Levinson's (1987) theoretical notions of face-preservation and face-threat, in that each former alternative promotes affiliation by preserving face, whereas each latter alternative promotes disaffiliation by threatening face.

Thus, preference is based on the possibility of alternative relevant actions (Lerner, 1996:304) such as the accept or decline alternatives available to Charles in designing his response to Nina in Excerpt 1. Consider the import of these two alternative SPP actions. To accept another's FPP offer (or invitation/proposal) is to align with it, go along with it, and thereby perform an affiliative, face-affirming SPP action that is supportive of social solidarity. ${ }^{1}$ But to decline another's FPP offer (or invitation/proposal) is a distancing action (Schegloff, 2007:59) that hinders the accomplishment of the activity proffered by the FPP, and thus constitutes a disaffiliative, face-threatening SPP action that is destructive of social solidarity (Heritage, 1984:268). Clearly, these alternatives are not equally-valued (Heritage, 1984; Schegloff, 2007; Pillet-Shore, 2010; 2011). Because one alternative is face-affirming/preserving and

\footnotetext{
${ }^{1}$ Although Schegloff (2007:60) observes that "generally it appears that accepting is the preferred response to offers," he and others (e.g., Pomerantz \& Heritage, 2013) warn analysts to not take away from this an oversimplified and distorted notion that participants orient to a single preference principle as applying to all instances of an action (like offering). Instead, when responding to a prior utterance, participants infer the intent of the prior speaker and take into account the action being done (e.g., offering, including consideration of the referent being offered, e.g., "the last piece of pie"), the precise way it is designed (e.g., formulated as "the last piece"), and the context of the offer (e.g., delivered to a guest by a dinner host who has not yet had a piece) to determine the preference principles that are most relevant.
} 
affiliative, and the other is face-threatening and disaffiliative, participants characteristically perform each with a different set of design features.

On the one hand, participants doing affiliative actions (e.g., SPPs that do accepting/granting; FPPs that do offering) usually design their utterances simply and straightforwardly - without delay, qualification/mitigation, or account. The CA term for these properties of turn/sequence design is "preferred". On the other hand, participants doing disaffiliative actions (e.g., SPPs that do declining/refusing; FPPs that do requesting) regularly delay, qualify/mitigate, and/or account for their utterances/actions. The CA term for this alternative non-straightforward turn/sequence design is “dispreferred" (Heritage, 1984; Schegloff, 2007). We can see this pattern in participants' design of both sequence-responding and sequence-initiating actions.

\section{Sequence-Responding Actions}

Excerpts 2 and 3 , which both show invitation sequences, exemplify this contrast. In Excerpt 2, Bella's utterance at line 3 is a FPP that does the action of inviting Ann to her home at some unspecified time.

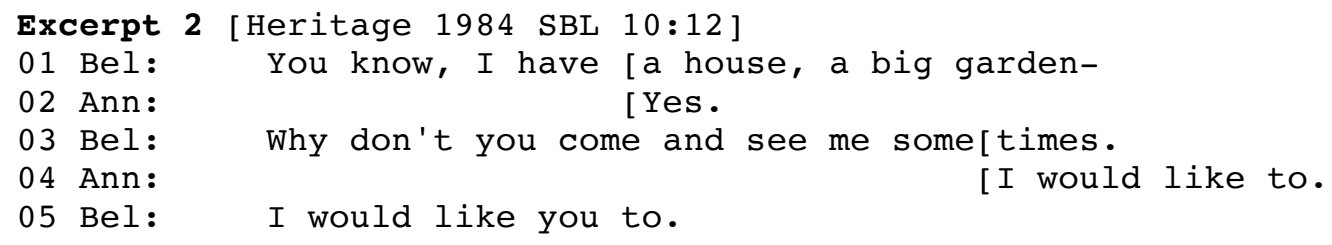

At line 4 above, Ann's response does the action of accepting Bella's invitation (Heritage, 1984), designing her SPP utterance simply and straightforwardly. And the timing of Ann's response is an important design feature: she starts her acceptance early, in overlap with Bella's inviting utterance. Thus, we can describe Ann's utterance at line 4 as performing a "preferred" action in the "preferred" design format. 
In Excerpt 3, Bella's utterance at lines 1-2 is a FPP that invites Ann to visit her that morning and also offers her coffee.

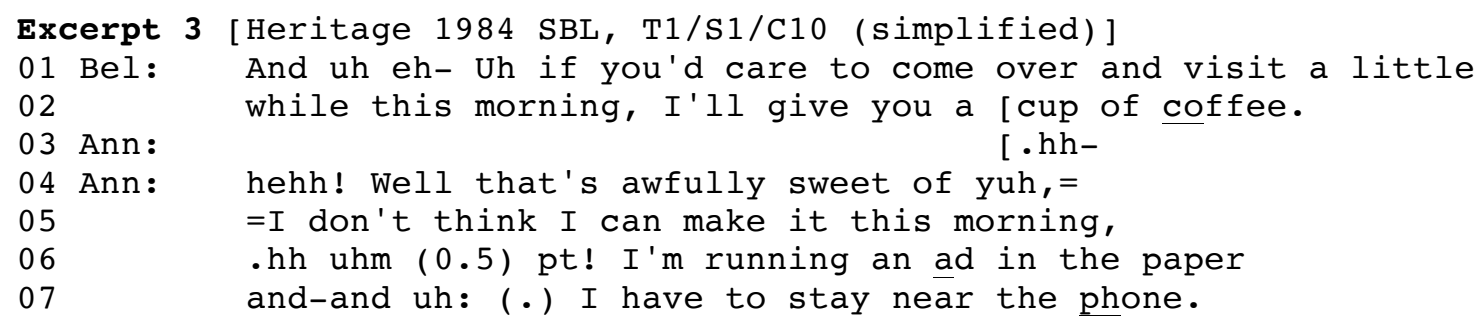

At lines 3 through 7, Ann does the action of declining Bella's invitation (Heritage, 1984:266), designing her SPP utterance non-straightforwardly. In contrast to her early acceptance in Excerpt 2-line 4, Ann delays the portion of her SPP that does the declination/refusal (“I don't think I can make it this morning,") by first (i) producing an audible breath/laugh token (.hh- hehh!), (ii) delivering a turn-initial "Well" (which works to alert the recipient to an incipient non-straightforward and/or dispreferred action; Schegloff \& Lerner, 2009), and then (iii) delivering an utterance that does the action of appreciating Bella's preceding action ("that's awfully sweet of yuh,"). Also relative to her simple acceptance in Excerpt 2, Ann's utterance in Excerpt 3-line 5 is qualified and mitigated: she marks it as uncertain with "I don't think" (though it is still non-negotiable), and she invokes an inability (rather than an unwillingness) to accept (saying "I don't think I can" rather than "I don't want to"). Finally, compared with her acceptance in Excerpt 2 which she treats as not requiring an account/explanation, Ann treats her declination/refusal in Excerpt 3 as requiring an account, which she provides at lines 6-7 (note that this recording predated mobile phones). Thus, we can describe Ann's utterance at lines 3 through 7 as performing a "dispreferred" action in the "dispreferred" design format. 
These different sets of design features - with "preferred" actions being produced straightforwardly, and "dispreferred" actions being produced non-straightforwardly (with delay, qualification/mitigation, and/or account) - are not idiosyncratic to certain participants, or even to certain action sequences. They are observable during sequences involving invitations, proposals, offers, requests, and other action sequences including personal assessments (e.g., self/other praise/criticism) (Pillet-Shore, 2012a; 2015a; 2016), (dis)agreements, (dis)confirmations (Pomerantz, 1984; Sacks, 1987) and corrections (Schegloff, Jefferson \& Sacks, 1977). These are highly generalized, systematic and institutionalized ways of speaking and interacting (Heritage, 1984:267). Thus, if we reconsider Excerpt 1, we can see that Charles performs the preferred action of accepting Nina's offer in the preferred design format: he times his response so it starts early (in overlap with her offer), and he deploys a prosodically and lexically definitive (certain, unqualified) and enthusiastic acceptance that begins with "Ye:ah." in turn-initial position, contiguous with the offer.

Given the fact that participants regularly build their dispreferred utterances with accounts and delays, it is important to register two additional observations about how and why they use these design features. Most accounts have a 'no fault' quality (Heritage, 1984:270-71) - they tend to invoke the speaker's inability rather than unwillingness (the latter being comparatively face-threatening) to perform the alternative affiliating action. And delays (e.g., via silence, or turn-initial particles like well, uhm) hearably foreshadow disaffiliating, face-threatening actions and thus can alert FPP speakers to an upcoming dispreferred action (cf. Kendrick \& Torreira, 2015). FPP speakers can use the time afforded by a delay to revise the original FPP (e.g., to be 
more attractive/acceptable), or to formulate an anticipation of disconfirmation/rejection (thereby mitigating the face-threat of that imminent rejection). In sum then, while participants' early or on time delivery of preferred actions maximizes the likelihood of their occurrence (Pomerantz, 1984), their delayed delivery of dispreferred actions minimizes the likelihood of their occurrence by enabling the possibility that they will be preempted (Heritage, 1984:276). ${ }^{2}$

\section{Sequence-Initiating Actions}

CA work has uncovered a preference organization of sequence-initiating actions, elucidating several different types of FPP that tend to be performed either in the preferred design format (i.e., simply/straightforwardly, and without delay, qualification/mitigation, or account) or in the dispreferred design format (i.e., with delay, qualification/mitigation, and/or account).

Much like preferred SPPs, preferred FPPs tend to be delivered as soon as possible, at the earliest moment in the interaction when they may be initially relevantly performed. Preferred sequence-initiating actions include:

- offering something of value (Schegloff, 2007; Pillet-Shore, 2010; 2011)

- recognizing a familiar person (Schegloff, 1979; 2007; Pillet-Shore, 2012b)

- registering a recipient's positively-valued referent (Schegloff, 2007; Pillet-Shore, 2005; 2008; 2016)

- registering one's own negatively-valued referent (Pillet-Shore, 2005; 2015a, 2016)

- praising an addressed-recipient (Pillet-Shore, 2012b; 2016)

\footnotetext{
2 Extant literature implies the existence of a preference matrix containing both congruent and incongruent possibilities. Congruence occurs when a person produces a preferred action with preferred design features (as in Excerpts 1 and 2), or when a person produces a dispreferred action with dispreferred design features (as in Excerpt 3). Incongruence occurs when a person produces a preferred action with (some) dispreferred design features (e.g., accepting an invitation after some delay, which can sound 'reluctant'), or when a person produces a dispreferred action with some preferred design features (e.g., declining/rejecting an invitation/offer/proposal/request quickly or without mitigation or account, which can sound 'rude'; Heritage, 1984:268; Sidnell, 2010:86). I return to this issue in the Future Directions section.
} 
As just one example of a preferred sequence-initiating action, Excerpt 1 shows host Nina offering a beverage to arriving guest Charles simply, straightforwardly, and at the earliest moment in their interaction when this may be done (only 14-seconds after he walks through her door, and just after they have exchanged greetings and personal state inquiries).

Correlatively, much like dispreferred SPPs, dispreferred FPPs tend to be withheld or delayed relative to points in the interaction when they might otherwise have been initially relevantly performed (Robinson \& Bolden, 2010: 503). Dispreferred sequence-initiating actions include:

- requesting something of value (Schegloff, 2007; Pillet-Shore, 2010; 2011)

- self-identifying to a familiar person (Schegloff, 1979; Pillet-Shore, 2011)

- registering a recipient's negatively-valued referent (Schegloff, 2007; Pillet-Shore, 2005; 2008; 2016)

- registering one's own positively-valued referent (Pillet-Shore, 2005; 2012a; 2015a; 2016)

- self-praising (Pillet-Shore, 2012a; 2015a)

- criticizing an addressed-recipient (Pillet-Shore, 2016; Pomerantz, 1978a; 1984)

- correcting an addressed-recipient (Schegloff, Jefferson \& Sacks, 1977)

- explicitly soliciting an account for an addressed-recipient's conduct with a whytype interrogative (Robinson \& Bolden, 2010; Bolden \& Robinson, 2011)

- giving unsolicited advice to an addressed-recipient (Heritage \& Sefi, 1992)

As just one example of a dispreferred sequence-initiating action, Excerpt 4 shows caller Donny implying, but never explicitly articulating, a FPP request (for assistance from Marcia) through his utterances at lines 4, 6, 9-10, 12-13 and 15.

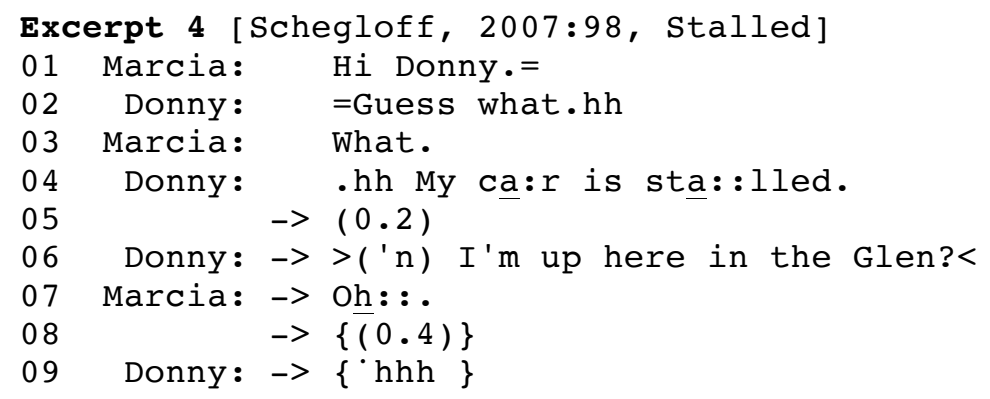




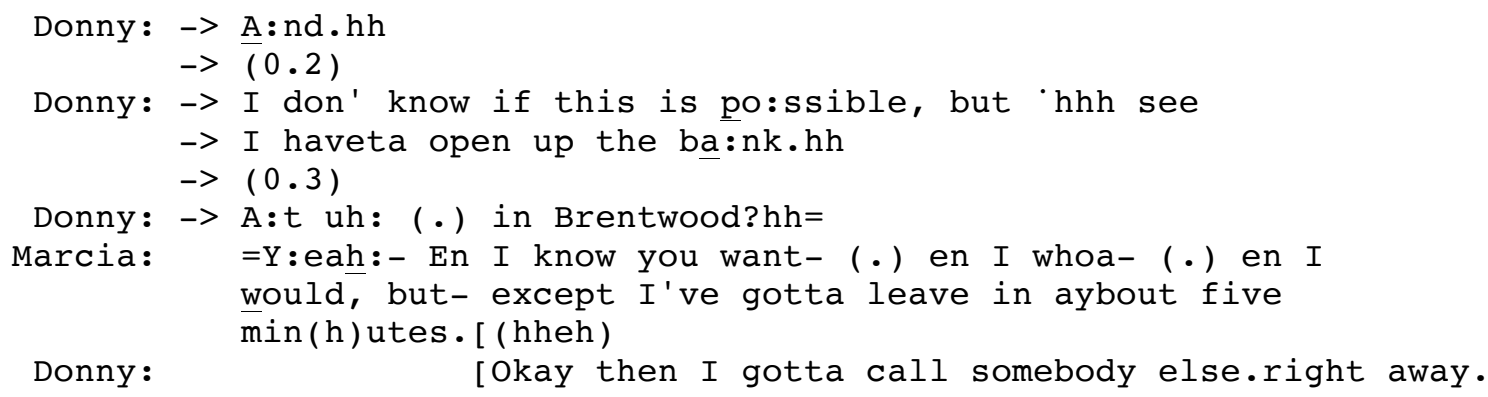

The arrows in Excerpt 4 indicate points in the interaction when Donny could have produced - but instead chooses to withhold - a request, thereby displaying his orientation to it as a dispreferred FPP action. (The arrows also indicate points when Marcia could have produced - but instead chooses to withhold - an offer. Thus this sequence also shows Marcia implying but never articulating a dispreferred response at lines 16-18 - it too is mitigated "to the vanishing point"; Schegloff, 2007:64.)

While participants' delayed delivery of dispreferred sequence-initiating actions minimizes the likelihood of their occurrence by enabling the possibility that they will be preempted (by a more preferred alternative), participants' as-soon-as-possible production of preferred sequence-initiating actions maximizes the likelihood of their occurrence.

\section{Pre-sequences}

Even before a participant begins delivering a FPP action, s/he can do preliminary work to forestall the possibility of a dispreferred SPP. Schegloff (2007:28-37) observes that, en route to doing social actions including inviting, offering, and requesting, speakers recurrently deploy preliminaries (e.g., pre-invitations, pre-offers, and prerequests) - utterances that project specific imminent FPPs. Pre-sequence FPPs (e.g., "Are you gonna be around this weekend?") are designed to help prospective producers 
of an incipient invitation/offer/request (etc.) avoid a dispreferred, face-threatening response.

Consider Excerpt 5, which shows the opening of a telephone conversation between caller Nelson and Clara.

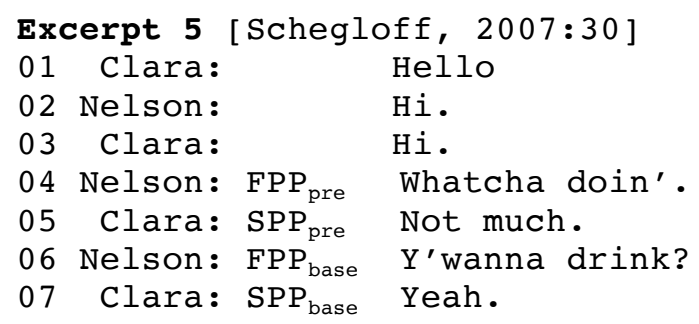

Nelson's utterance at line 4 works as a pre-invitation/pre-proposal FPP. Clara responds at line 5 with a "go-ahead" - a pre-sequence SPP response that encourages its recipient to proceed by delivering the projected (base) FPP. Nelson produces this base FPP invitation/proposal at line 6 , to which Clara responds at line 7 by doing the action of accepting Nelson's invitation/proposal with preferred design features - simply and straightforwardly (without delay or account).

In addition to "go-ahead" responses, recipients of such preliminary FPPs can also deliver "hedging" responses (e.g., "Why?") or "blocking" responses - those that indicate other commitments and thus discourage an incipient invitation/request (e.g., if Clara had said at line 5, "Studying for my final exam tomorrow"). These pre-sequences thus enable participants to circumvent rejection.

\section{KEY PREFERENCE PRINCIPLES}

CA research has discovered several general preference "principles" (Pomerantz \& Heritage, 2013:210) that observably guide how participants design their social actions in interaction. There are occasions when more than one preference principle is 
operative - when participants orient to concurrent preferences. Although concurrent preference principles may converge, in some cases they conflict, tacitly guiding the participants to act in divergent ways. This section presents an overview of key preference principles, and describes how participants manage concurrent, conflicting preferences.

This section describes the following preference principles:

- the preference for recipient design

- the preferences for contiguity and agreement

- the preference for progressivity

- the preference for offers over requests

- the preference for recognition over self-identification

- the preference for self-correction over other-correction

- the preference for self-criticism over other-criticism (the preference to avoid other-criticism)

- the preference for other-praise over self-praise (the preference to avoid selfpraise)

\section{Preference for Recipient Design}

A fundamental principle underlying every action participants do in interaction is "recipient design" (Sacks, Schegloff \& Jefferson, 1974:727): that is, participants should tailor their actions to their specific addressees. This principle pervasively informs how speakers prosodically and lexically design their utterances. Indeed, some of the most delicate recipient design work occurs on the level of prosody (the 'musical' aspects of speech, including pitch, loudness, duration). For example, when opening interaction, participants hearably tailor the prosodic aspects of their greeting utterances to target recipients such that they display a stance toward the current state and character of their relationship (Pillet-Shore, 2012b). The principle of recipient design guides speakers to tailor their talk so it is both recognizable/understandable to addressees, and also respects the "constraint on telling" Schegloff (2007: 38) that talk should not convey 
information (positioned as 'news') that recipients (likely) already know (Goodwin, 1979:100).

A robust body of CA work has demonstrated that recipient design informs how speakers describe and refer to persons (e.g., Sacks \& Schegloff, 1979; Schegloff, 1996; Stivers, Enfield \& Levinson, 2007), places (e.g., Schegloff, 1972), events (e.g., Sacks, 1992; Drew, 1992) and time (e.g., Enfield, 2013). In each case, given the fact that a speaker must select from among a variety of possible and equally correct alternative ways of describing or referring, a speaker should select a description/reference that s/he expects the addressed-recipient to know or recognize (Sacks, 1992:II:148), thereby satisfying the preference for recipient design via recognition.

Person reference is a domain that has received extensive attention in CA work. When selecting how to refer to a particular person, speakers have a wide variety of forms from which to choose. (For example, I might refer to my husband as Jeff, my spouse, him/his, someone, Stella's dad, my best friend, etc.). Speakers select from two basic options: (i) recognitional (intended to be recognizable to recipients) person reference forms, often personal names (e.g., "Henry and Leo") or recognitional descriptors (e.g., "the identical twins who come in here every Sunday"), or (ii) nonrecognitional forms (e.g., "some kids," "these two boys").

Excerpt 6 shows a speaker using two different reference forms to refer to the same nonpresent person. Five participants are gathered in the living room of an apartment discussing two celebrity gossip magazines, People and Us Weekly. Leading up to this excerpt, Meg has announced, "People tells me everything," to which Peg 
responds, "I'm more of a U.S. [sic] Weekly kinda girl." Peg then delivers the utterance starting at line 1.

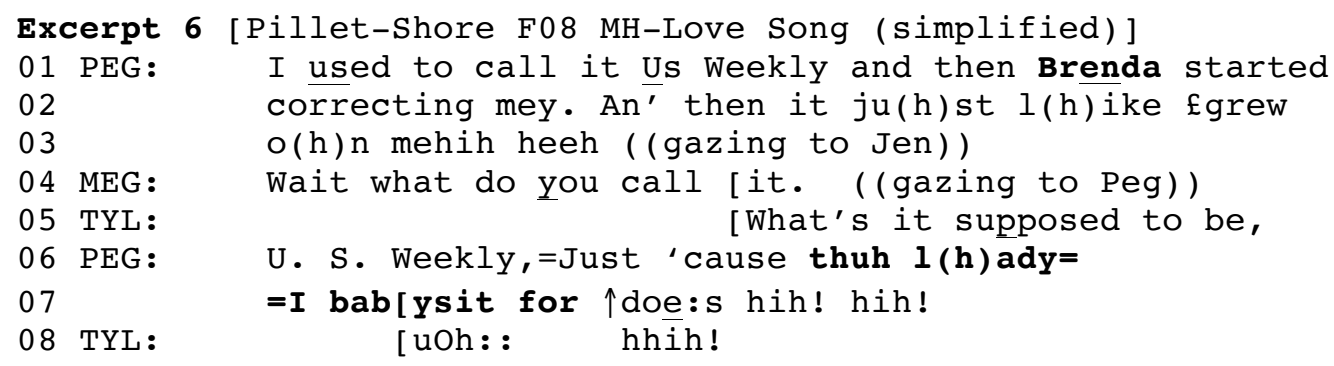

At line 1, and at lines 6-7, Peg refers to the same, nonpresent person using two different reference forms, each of which is recipient designed or tailored for her current addressee. At line 1, while gazing at and directing her talk to her roommate Jen, Peg selects "Brenda", a personal name that works as a recognitional person reference form - one that Peg expects her current addressed-recipient Jen to recognize. At lines 6-7, however, while gazing at and directing her talk to her friends Meg and Tyler, Peg selects an alternative reference to this same person, choosing the recognitional descriptor "thuh I(h)ady I babysit for". Thus, Excerpt 6 shows how Peg selects from equally correct alternative ways of describing or referring to the same person, in each case choosing a reference that she expects her addressed-recipient to know or recognize, thereby satisfying the preference for recipient design via recognition.

Although reference forms are combinable, there is a preference for minimization: speakers should use a single reference form (Sacks \& Schegloff, 1979; Stivers, Enfield \& Levinson, 2007:11). At the same time, there is a preference for recognition: if possible, speakers should use a reference form that the recipient can recognize. When speakers use (and their recipients recognize) a personal name, they simultaneously satisfy these two preferences. But when these two preferences come into conflict - for 
example, if the recipient does not display recognition of the first-deployed name - then the preference for minimization is relaxed step-by-step such that the speaker adds incremental referring expressions (e.g., a last name, a description) until the recipient displays successful recognition.

Recent work (e.g., Stivers, Enfield \& Levinson, 2007; Pillet-Shore, 2011) suggests that, in addition to the preferences for minimization and recognition, there is a third preference principle that informs how speakers refer to copresent and nonpresent persons - the preference for association: when possible, speakers should connect (or associate) the referent (the person being referred to/formulated) directly to the current recipient(s). ${ }^{3}$

\section{Preferences for Contiguity and Agreement}

This section describes the preferences for contiguity and agreement in three different sequence types: polar question-answer sequences, assessment sequences, and storytelling sequences.

In polar question-answer sequences

Analyzing how speakers produce and respond to polar questions (i.e., questions that can get a 'yes' or a 'no' answer, also known as yes/no interrogatives, or candidate answer questions), Sacks (1987) observed that there are two concurrent preferences: a preference for contiguity, and a preference for agreement.

The preference for contiguity guides where within a turn-at-talk (the beginning, middle, or end) speakers deliver a question and answer constituting an adjacency pair

\footnotetext{
${ }^{3}$ For example, see Excerpt 14-line 4.
} 
sequence: when a question occurs in a turn that includes other things, speakers recurrently place that question at the end of the turn. Correlatively, when an answer occurs in a turn that includes other things, speakers recurrently place that answer at the beginning of the turn. It is through questioners' and answerers' independent design of their respective utterances that they can collaborate to produce answers as contiguous with the questions that elicited them.

The preference for agreement (or confirmation) guides how speakers design their responses to polar questions depending on whether they are selecting an agreeing/confirming, or disagreeing/disconfirming, response. Speakers tend to deliver responses that agree with or confirm the candidate answer proffered by the question immediately such that their agreement/confirmation is contiguous with the FPP question. In contrast, speakers tend to defer the components of their responses that disagree with or disconfirm the candidate answer, thereby breaking contiguity.

We can see these phenomena in Excerpt 7. At lines 1-2, Speaker A first assesses (and moves to close) a prior sequence, and then asks two questions. The first question, "how is yer arthritis" is a Wh-question (how belongs to a larger class of openended question words, also including who, what, where, when, and why) that makes relevant a response that assesses/describes. The second question, "Yuh still taking shots?" is a polar question that makes relevant one of two possible response types: either a confirming response or a disconfirming response.

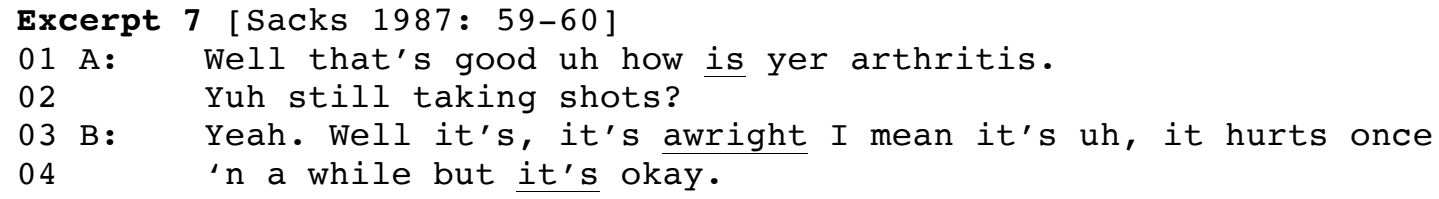


In designing the response at lines 3-4, Speaker B first answers Speaker A's second question. By beginning line 3 with "Yeah", Speaker B preserves contiguity with the question at line 2, and confirms the candidate answer proffered by that question.

Excerpt 8 shows a contrast case. After Speaker A issues a polar question at line 1 , Speaker B responds by deferring or delaying the disconfirming/disagreeing portion of the response ("I w- probably won't be too early") until near the turn's end at line 3, thereby breaking contiguity.

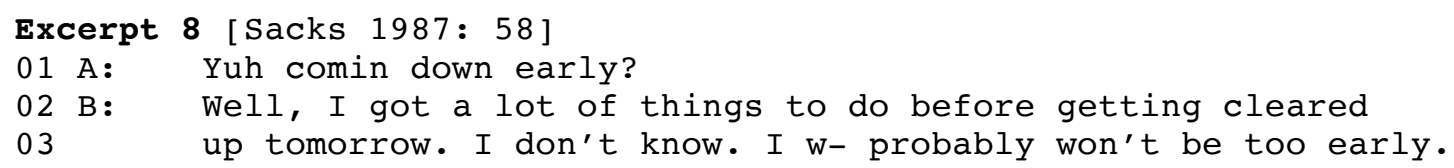

Thus, recipients of polar questions treat their own disconfirming/disagreeing responses as dispreferred through regular design features that break contiguity (e.g., turn-initial delays including well and $u \mathrm{hm}$, and pre-positioned accounts, appreciations, and markers of uncertainty) - design features that also mitigate the projected facethreatening disconfirmation/disagreement. Because these delaying design features (after questions) hearably portend disagreement/disconfirmation, they can prompt FPP speakers to reformulate their questions to make a confirming answer more likely.

Excerpt 9 exemplifies this pattern. At line 1, Speaker A asks a polar question that exhibits a preference for a response that confirms an ability to walk. But after a silence develops at line 2, Speaker A revises the question so, at line 3, the revised version exhibits a preference for a response that confirms an inability to walk.

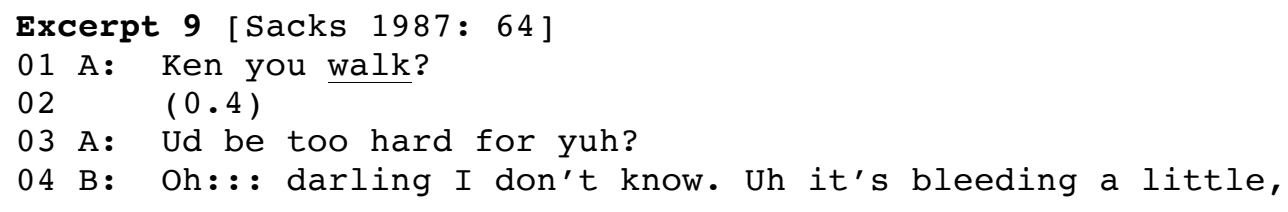


Speaker A thereby displays an understanding of the emerging silence at line 2 (constituting broken contiguity) as foreshadowing an upcoming dispreferred response, working to forestall the delayed disconfirmation by redesigning the question so it is more likely to get a preferred, confirming response.

It is not only speakers' SPP responses to polar questions that can be described in terms of preference; speakers' FPP polar questions themselves can also be described as incorporating preferences. Based on how a speaker designs a polar question grammatically and lexically, that speaker can hearably build it to prefer either a 'yes' or a 'no' answer (that, in each respective case, would be the confirming response).

Questions that are affirmatively-framed (as a simple interrogative, e.g., Are you married?; a positive declarative, e.g., You're married.; a positive declarative plus negative tag, e.g., You're married, aren't you?; or a negative interrogative, e.g., Aren't you married?) prefer a 'yes' response. Questions that are negatively-framed (as a negative declarative, e.g., You're not married.; a negative declarative plus positive tag, e.g., You're not married, are you?; or a simple interrogative with negative polarity, e.g., lexical items including any, ever, yet, at all) prefer a 'no' response. Excerpt 10 shows Bee to deliver a polar question designed as a simple interrogative with the negative polarity item "yet" at line 1. Thus, Bee's question is built to prefer a 'no' response.

Excerpt 10 [Schegloff 2007: 62, TG]

01 Bee: Did they geh ridda Kuhleznik yet hhh

02 Ava: No in fact I know somebuddy who ha:s huh now.

At line 2, Ava delivers a 'no' response - one that she produces as preferred by delivering it immediately and contiguously with the question.

In addition to the aforementioned preferences, polar questions also carry a "typeconformity" preference: by its very grammatical design, a yes/no interrogative prefers a 
response that includes a 'yes' or a 'no' item. A response that includes a 'yes' or a 'no' is "type-conforming", whereas a response that withholds a 'yes' or a 'no' is "nonconforming" (Raymond, 2003). Reconsidering Excerpt 10, we can see that, because Ava's response includes a 'no' it is type-conforming and thus preferred on this additional analytic level. (The response in Excerpt 1-line 3, and in Excerpt 7-line 3, show other cases.) In contrast, reconsidering Excerpts 8 and 9, we can see that speakers deliver nonconforming responses (in Excerpt 8-lines 2-3; and in Excerpt 9-line 4), and thus these responses are dispreferred on this additional analytic level.

CA work has extensively examined polar question sequences in ordinary conversation, as well as in various institutional settings, including medical contexts (e.g., Boyd \& Heritage, 2006), legal settings (e.g., Drew, 1992), and news interviews (e.g., Clayman, 1993; 2001). There is considerable empirical evidence that speakers design polar questions to enable recipient confirmation, and that recipients build their responses to maximize confirmation and minimize disconfirmation. In a study examining ten languages, Stivers, et al. (2009) shows that, across all languages, confirming answers are more common and disconfirming answers are delayed. Speakers can, however, relax the aforementioned preference for a confirming response by appending a turn-final or to the end of a polar question (Drake, 2013).

\section{In assessment sequences}

Analyzing how impersonal assessments work in interaction, Pomerantz (1984) shows that, when speakers assess a referent that is accessible to their recipient, that recipient should respond by producing a second assessment that either agrees or disagrees with the first. Once again, however, participants to interaction do not treat 
these agree or disagree alternatives as equally valued. Consistent with the preceding discussion, parties typically treat second assessments that agree as preferred over those that disagree.

Excerpt 11 exemplifies an impersonal assessment sequence. At line 1, Jeff produces a FPP utterance that positively assesses the day's weather - a referent to which his recipient Trent shares concurrent access.

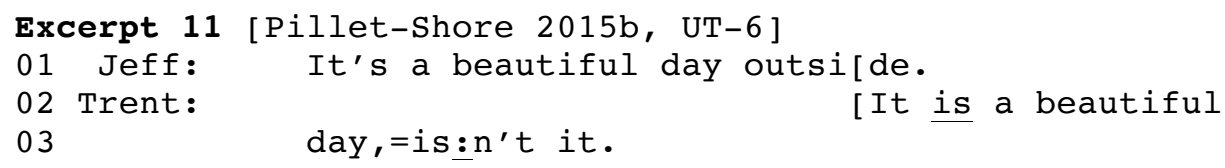

At lines 2-3, Trent produces a preferred response, immediately (in terminal overlap) delivering a second assessment that agrees with Jeff's first assessment by asserting the same evaluation as the prior speaker (marking it as second with contrastive emphasis on "is").

While Pomerantz (1984) argues that the majority of first assessments prefer agreement, she notes two exceptions pertaining to personal assessments: selfdeprecations (self-criticisms), and compliments, both of which generally prefer disagreement.

A self-deprecation is a speaker's expression of a negative/criticizing stance toward some referent attributable to self, which can be done through a negative assessment utterance. Excerpt 12 shows $B$ self-deprecating at lines 1 and 3 by negatively assessing her own bridge-playing skills.

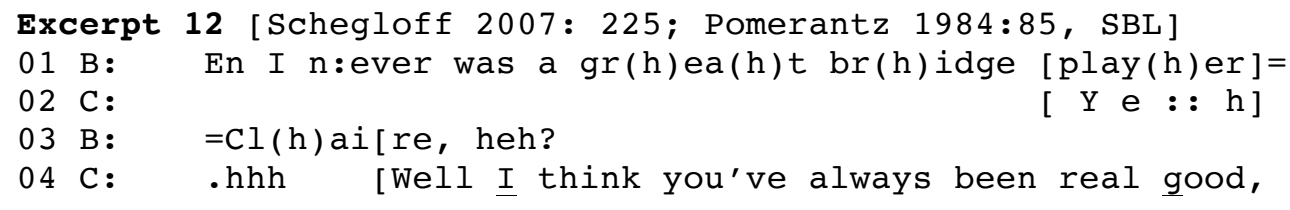

At line 4, C responds to B's self-deprecating FPP by disagreeing with it. C launches her 
utterance at line 4 with an audible breath and a turn-initial well (which projects the incipient disagreement), and then uses contrastive stress on "l" to underscore her own countervailing positive assessment of B's bridge prowess. Thus, to do the preferred disagreement with B's preceding self-deprecation, C compliments B.

A compliment is a speaker's expression of a positive/praising stance toward some referent attributable to her/his addressed-recipient (Pillet-Shore, 2015b). Because speakers often deliver compliments through utterances that assess, a complimenting FPP is analyzable as preferring a SPP that agrees with it. In addition, a compliment constitutes an offer of support or approval - an action that prefers a SPP that accepts. These converging, congruent preferences for agreement and acceptance are not, however, the only preferences operative during complimenting sequences. Pomerantz (1978b) argues that complimenting FPPs also make relevant a conflicting preference for compliment-recipients to avoid self-praise. ${ }^{4}$ Precisely because these multiple preferences - to avoid self-praise on the one hand, and to accept and agree with the compliment on the other - are at odds with one another, compliment-recipients are in an interactional bind when producing a response: they must work to design their response so it displays a sensitivity to all of these incompatible constraints.

Pomerantz (1978b) describes various ways that compliment-recipients can manage these conflicting constraints. One recurrent solution response type is appreciation, exemplified in Excerpt 13. At line 1, Travis delivers a FPP complimenting utterance by positively assessing his recipient Jason's appearance. At line 2 Jason produces a SPP compliment response.

Excerpt 13 [Pillet-Shore UT-4]

${ }^{4}$ For additional detail, see the section on the Preference for Other-Praise over Self-Praise below. 


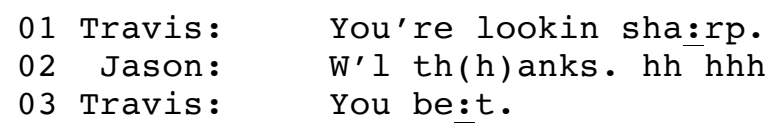

Jason's response at line 2 begins with a turn-initial well followed by an appreciation ("th(h)anks"), which he produces with infiltrating and post-completion laugh particles (Pillet-Shore, 2012a; 2015b). Through this response design, Jason displays his sensitivity to the preference to accept and agree with Travis's compliment while at the same time avoiding self-praise by avoiding saying anything semantically fitted to its specifics.

In storytelling sequences

When speakers tell stories in conversation, they both display a stance toward the events they are reporting, and make relevant a recipient display of stance at story completion (Stivers, 2008). A basic stance that recipients can display is constituted in whether or not they treat the story as "sequentially implicative": the preferred response is for recipients to show that they are using the story "as a source for triggered or topically coherent subsequent talk" (Jefferson, 1978: 228), rather than treating the story as having little relevance to the ongoing talk (the dispreferred alternative response).

Relatedly, storytelling recipients can respond at a story's end in a way that either mirrors, or does not mirror, the storyteller's stance toward the reported events (often conveyed in a story preface that initially characterized the upcoming story as, for example, funny, weird, sad, etc.). Again, these two possible alternative responses are not equally valued: the preferred response is for the recipient to mirror - and thereby agree with - the teller's stance toward and treatment of the reported events (Sacks, 1974; Stivers, 2008). This finding applies to storytelling as well as to other forms of 
extended telling, such as the telling of a joke: Sacks (1974: 348) shows that, among the three primary responses possible at joke completion - immediate laughter, delayed laughter, and silence - immediate laughter is the preferred response (having "a priority claim on a joke's completion") because (whereas silence and delayed laughter treat the joke as 'not funny') immediate laughter treats the joke as 'funny' and thereby shows that the recipient(s) agree with the joke teller's stance toward the telling.

\section{Preference for Progressivity}

The preference for "progressivity" refers to an empirical bias toward forward movement in ongoing talk. This preference is observable, for example, when one participant is manifesting trouble finding a word (i.e., doing a word search) and fellow interactant(s) provide candidate words to help the turn resume its forward progress (Goodwin \& Goodwin, 1986). This preference is also observable following a question in multi-party interaction (involving three or more participants). In such a situation, there are two concurrent preferences that bear on progressivity: (i) a preference for an answer over a non-answer, and (ii) a preference for the selected speaker to take the next turn. Stivers \& Robinson (2006) show that when these two concurrent preferences cannot be satisfied simultaneously (because the selected speaker can/does not produce an answer), the preference for progressivity wins - a non-selected participant regularly delivers an answer to move the talk forward.

\section{Preference for Offers over Requests}

In accomplishing the transfer of something of value from one person to another, 
there is a preference for offer sequences over request sequences (Schegloff, 2007: 82). Valued tranferables include objects (e.g., a borrowed coat on a cool night, money, food/beverage), services (e.g., help, transport), and information (e.g., about fellow participants; Pillet-Shore, 2010; 2011). In other words, the most preferred state-ofaffairs occurs when the person who has the valued transferable offers it spontaneously as a sequence-initiating action, rather than the potential recipient requesting it through a FPP.

In terms of timing, request FPPs tend to be delayed, appearing "disproportionately to occur late in conversations" (Schegloff, 2007:83). ${ }^{5}$ Analyzing telephone conversation, Schegloff (2007:83) observes that, "some phone calls which appear (in retrospect upon their completion) to have been made specifically to do a request may have several topics raised, and other sequences worked through, before the request is articulated." In addition, speakers tend to perform requesting FPPs in the dispreferred design format, positioning accounts and mitigations before they articulate an explicit request (thereby deferring the request itself; see Excerpt 4).

Correlatively, offer FPPs tend to be delivered at the earliest moment in the interaction when they may be initially relevantly performed. In addition, offering FPPs are performed in the preferred design format: simply/straightforwardly, and without turninitial delay, qualification/mitigation, or account. For example, when guests arrive to hosts' homes, participants produce offers of comfort and consumables simply, straightforwardly, and as soon as possible, just after completing greeting and personal state sequences (Pillet-Shore, 2008). Recall that in Excerpt 1, host Nina offers guest

\footnotetext{
${ }^{5}$ See Kendrick \& Drew (2014) for a dissenting view.
} 
Charles a cup of coffee only 14 -seconds after he walks through her door.

When opening face-to-face interactions more generally, participants also treat offers of information as highly valued and thus as preferred over requests for that information (Pillet-Shore, 2010; 2011). For example, when launching introducing sequences through which participants explicitly identify self and/or other, participants treat offers of information identifying unacquainted persons as strongly preferred over requests for that information (Pillet-Shore, 2011). This preference is observable both in how known-in-common mediators initiate introductions between two unacquainted parties - by offering information identifying unfamiliar persons immediately (as close as possible to the moment that they enter into one another's presence) - and in how unacquainted persons self-initiate introductions - by offering unfamiliar recipients selfidentifying information (e.g., "I'm Lilly") or candidate recipient-identifying information (e.g., "You're Teresa's friend").

Excerpt 14 shows an instance of a mediator initiating an introduction. Cohabiting sorority sisters Trisha, Jenelle, Kelsy and Sher are talking as they eat breakfast around the kitchen island in their house when two people arrive. One of the arrivers is Olexa $(\mathrm{OL})$, a fellow sorority sister. Immediately after Olexa exchanges greetings with her sorority sisters (lines 1 through 3 ), she acts as a mediator, initiating an introduction sequence at line 4 between her sorority sisters and the young man with whom she is arriving. Olexa times the start of her utterance at line 4 to the moment that the two unacquainted parties enter into one another's presence.

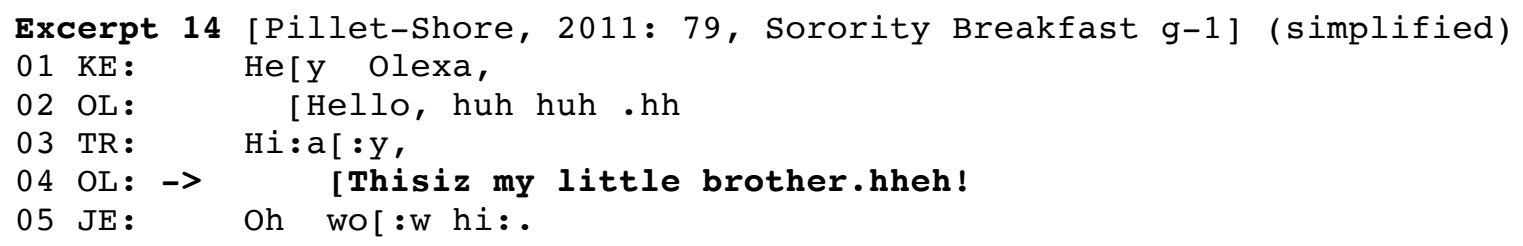


06 TR:

$07 \mathrm{KA}:$

$08 \mathrm{KE}:$

09 OL :

$10 \mathrm{OL}:$

$11 \mathrm{JE}:$

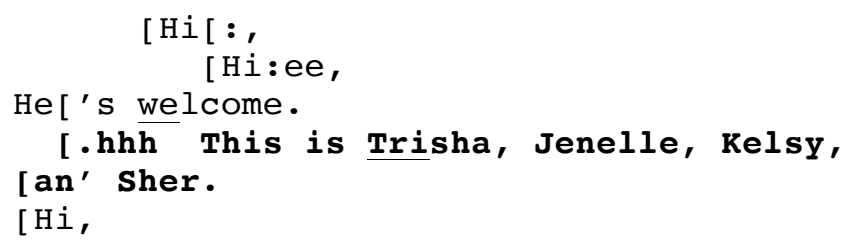

At line 4, Olexa offers information identifying her co-arriver, and at lines 9-10, she offers information identifying all pre-present persons.

Excerpt 15, which shows four people gathering to play cards, exemplifies a selfinitiated introduction. Leading up to line 1, the video shows guest Glenda (Gle), who is seated at the card table, counting a deck of cards as recently-arrived guest Gabe moves to stand next to her. After Gabe has been standing in that position for 11 seconds, Glenda self-initiates an introduction with Gabe at line 4.

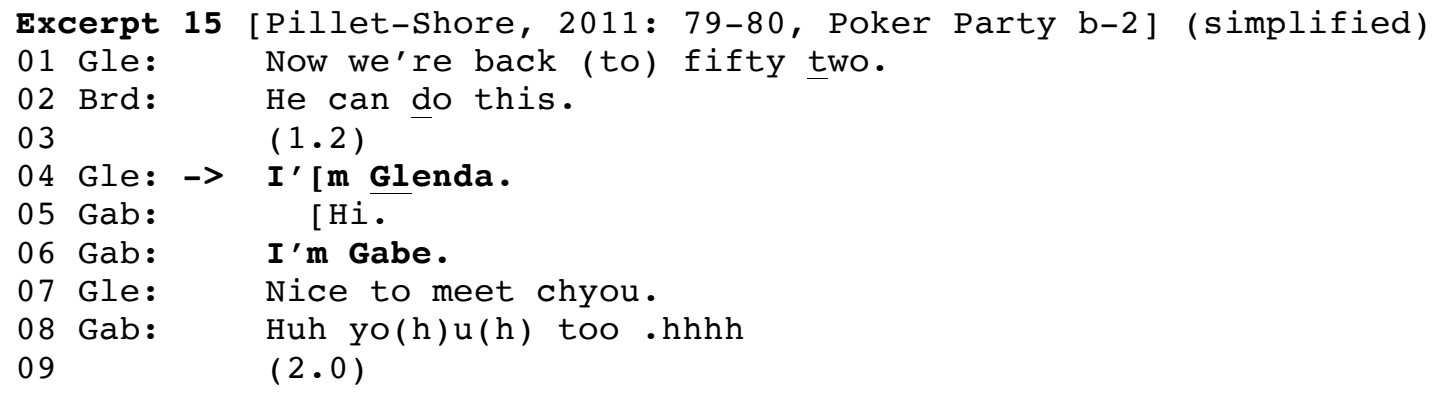

At line 4, Glenda offers Gabe self-identifying information by stating her own first name, an action he reciprocates at line 6. It bears mentioning that Glenda has alternatives available to her at line 4: she could have explicitly requested her recipient's identifying information - for example, by asking, 'What's your name?' or 'Who are you?' - but instead she chooses to offer him self-identifying information to implicitly invite him to reciprocate. Thus, when launching introducing sequences, offers of identifying information are strongly preferred over requests for identifying information.

The preference for offer sequences over request sequences is also observable when a newcomer enters some social scene where two or more already-present 
persons are actively engaged in an activity and that newcomer displays interest in joining their activity. In such a situation, participants have two alternative relevant actions available: (i) already-present person(s) may move to include the newcomer by offering information about their previous activity in the form of a "previous activity formulation" (Pillet-Shore, 2010), summarizing the activities or conversational topics in which they were engaged before establishing copresence with the newcomer (e.g., "We were just sharing Justin's math"; "We were just talking about what we we're gonna do or what you're gonna say"); or (ii) the newcomer may move to enter their conversation by requesting a previous activity formulation (e.g., "Wait.=What's this?" "What are you talking about?").

When already-present speakers offer a previous activity formulation to a newcomer, they do so early and straightforwardly, working to launch the formulation before or just at the moment the newcomer bodily displays readiness to coparticipate and join into the already-present party's interaction. In contrast, when a newcomer explicitly requests a formulation, s/he does so later after some delay, during which time the newcomer visibly waits and bodily displays interest in joining the already-present party's conversation (e.g., by sustaining gaze at and moving in closer toward alreadypresent persons). Thus, after newcomers arrive to an in-progress interaction, they do not rush to explicitly request that the already-present party produce a previous activity formulation for them. Rather, they delay, using tacit bodily resources to try to elicit an ostensibly offered formulation - further evidence of parties' orientation to offered formulations as preferred over requested formulations. Newcomers only resort to issuing an explicit request for a formulation if their tacit elicitation techniques fail. Pillet- 
Shore (2010) demonstrates that offers of previous activity formulations are preferred because such offers constitute an act of social inclusion that affirms participants' face and engenders social solidarity.

\section{Preference for Recognition over Self-Identification}

During the opening of an interaction, there is a preference for involved persons to recognize one another - if possible and relevant - over having to explicitly self-identify. Schegloff $(1979 ; 2007: 82)$ documents this preference for recognition in telephone conversation openings, showing that callers who are recognizable (via voice sample) to the answerer of the phone rarely self-identify. Complementing this work, Pillet-Shore $(2008 ; 2012 b)$ demonstrates the preference for recognition over self-identification in face-to-face interaction openings, showing that participants to incipient copresent encounters visibly hold off doing the action of greeting until they see 'who's there,' displaying their orientation to identification/recognition via visual inspection as prerequisite to producing a greeting (Pillet-Shore, 2008: 64-120).

As mentioned earlier, participants prosodically recipient design their greetings based on identification/recognition of current addressed-recipients, using a regular cluster of prosodic features (sound lengthening, audible smiling, increased volume, high onset pitch and a wide pitch span; Pillet-Shore, 2012b: 383-390) to treat recipients as familiar - a fast-and-frugal way of displaying successful recognition (Pillet-Shore, 2012b: 387). Through this cluster of prosodic features, participants maximize the likelihood of achieving greeting simultaneity, thereby satisfying the preference for doing greetings together (Pillet-Shore, 2012b: 390) - a state-of-affairs that is preferred 
because it enables involved persons to display approval and recognition of one another at the same time.

\section{Preference for Self-Correction over Other-Correction}

When people engage in conversation, they regularly encounter problems in speaking, hearing or understanding one another. CA work has identified an organized set of "repair" practices through which participants address and resolve these problems. Anything in participants' talk may be treated as in need of repair, independent of whether or not there are 'objectively' observable problems with the talk (Schegloff, 2007: 100).

Repair can be initiated and/or completed either by "self" - the speaker/producer of the trouble-source (i.e., the target problem in speaking, hearing or understanding), or by "other" - some other participant in the interaction. There is thus a matrix of possibilities for how repair can be initiated (by self or other) and completed (by self or other). Speakers can self-initiate repair, and then complete that repair, thereby engaging in self-repair/correction. When someone other than the speaker of the troublesource initiates repair, s/he engages in other-initiation of repair, and if that person then completes that repair, s/he engages in other-repair/correction. In addition to self-initiated self-repair, and other-initiated other-repair, participants may self-initiate other-repair (e.g., when a speaker solicits a recipient's help in searching for a word), or other-initiate self-repair (e.g., when a participant says "huh?" or "what?" to display that s/he has detected some trouble in another's preceding talk). But these possibilities are not equally likely to be observed. 
Schegloff, Jefferson \& Sacks (1977) document a "strong empirical skewing" toward self-repair or self-correction, noting the following observations: (i) current speakers have the first opportunity to both initiate and complete repair within their inprogress turns; (ii) other-initiations of repair are routinely withheld a bit past the possible completion of the turn containing the trouble-source; (iii) others typically only initiate repair, leaving it up to the speaker of the trouble-source to self-correct; and (iv) when other-correction does occur, it is often mitigated and/or done with other dispreferred design features. There is thus substantial evidence that (at least in adult peer conversation) there is a preference for self-correction over other-correction. ${ }^{6}$

\section{Preference for Self-Criticism over Other-Criticism (the Preference to Avoid Other- Criticism)}

CA work examining both casual and institutional interactions demonstrates that, if a criticism of a person is to be articulated, participants treat self-criticizing as preferred over other-criticizing.

This preference becomes manifest during sequences in which participants engage in the social action of "registering" by calling attention to some specific referent that is available for all participants' concurrent perception, including sights/sounds/smells of participants and physical surroundings (Pillet-Shore, 2005; 2008). "Registering" is an umbrella term that encompasses the often difficult to disaggregate actions of "noticing" and "announcing" (cf. Schegloff, 2007:82), including the linguistic and embodied ways in which participants call attention to mutually-

\footnotetext{
${ }^{6}$ Excerpt 6 , and the longer sequence from which it is taken, exemplifies these findings.
} 
perceivable referents. Participants produce and understand registering actions in ways that are sensitive to and take into account the owner of the referent (i.e., the participant regarded as most responsible for it), and the value or valence of the stance being taken up toward the referent. When participants orient to a specific referent as negativelyvalued (i.e., criticizable and/or complainable), they display their orientation to a preference for the person (most) responsible for that negatively-valued referent to be first to register it (rather than allowing a non-responsible person to call attention it; PilletShore, 2005; 2016:22).

Evidence of this preference is observable during the opening phase of casual face-to-face interactions, when speakers 'suddenly' explicitly register some negativelyvalued (criticizable) referent on their own bodies and/or in their own personal territories (e.g., the appearance or tidiness of a residence, car, or office) - a referent that, though held constant for the speaker (who does not index a change-of-state), has 'just now' become perceptible to addressed-recipient(s). In Excerpt 16, shortly after arriving to her friends' apartment, Hillary $(H)$, who is wearing shorts, registers a negatively-valued and mutually-perceivable referent on her own body at line 6 .

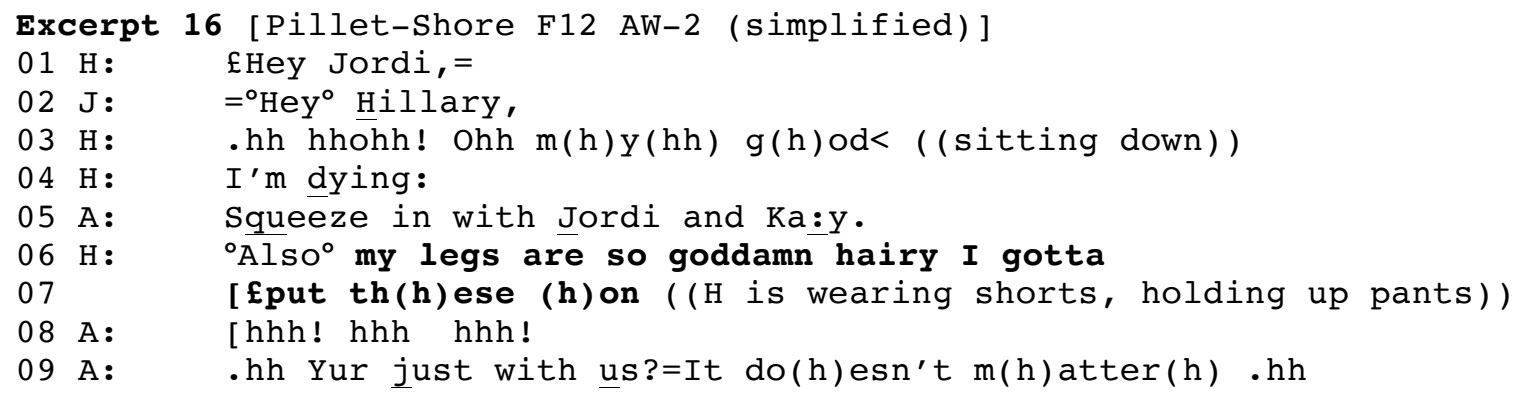

At line 6, Hillary calls her addressed-recipients' attention to her legs as being "so goddamn hairy", an action tantamount to self-criticizing/self-deprecating. She produces her utterance in the preferred design format, delivering it fluently and straightforwardly 
(i.e., without delay, mitigation, qualification, or uncertainty; cf. Pillet-Shore, 2016).

Through this registering action, Hillary preemptively articulates a criticizable referent for which she is responsible. Then, through her infiltrating laughter at line 7, Hillary invites others to laugh with her, transforming a potential for criticism-by-other into an interactional opportunity for affiliation around a self-criticism.

This preference is also observable during assessment sequences in which participants are evaluating a known-in-common referent. For example, during parentteacher conference interactions, although both parents and teachers deliver utterances that criticize nonpresent, known-in-common students/children, there is a marked contrast between how and when they each do this action. On the one hand, teachers regularly produce their student-criticizing utterances in the dispreferred design format non-fluently and non-straightforwardly, systematically delaying, qualifying/mitigating and/or accounting for their criticisms of students (Pillet-Shore, 2016). Teachers thereby treat their student-criticizing utterances as embodying the dispreferred action of othercriticizing. On the other hand, parents routinely criticize their own children in the preferred design format - fluently, straightforwardly and without delay, qualification/mitigation, or account (Pillet-Shore, 2015a). Parent-teacher conference participants thus display an orientation to parents as (most) responsible for the student/child, engendering a systematic structural preference for parents to preemptively articulate a particular student-trouble/criticism (rather than allowing the teacher to be first to express it; Pillet-Shore, 2015a; 2016).

Thus, the preference for parents to criticize their own children seems to be a specific manifestation of the more general preference for the person responsible for a 
negatively-valued referent to be first to call attention to it (Pillet-Shore, 2005; 2008).

Much as it is better for the maintenance of "face" (Goffman, 1967) and social solidarity if a dinner host/cook is first to comment upon the fact that the main course is overcooked, it is likewise better for the maintenance of all involved parent-teacher conference participants' "face" if the parent is first to comment upon her/his child's shortcomings, thereby enabling the teacher to avoid explicitly other-criticizing (Pillet-Shore, 2015a:393).

The preference to avoid other-criticism is also observable during sequences in which speakers explicitly solicit an account for an addressee's conduct (e.g., through a why-type interrogative). Robinson \& Bolden (2010) argue that explicit account solicitations are frequently critical of, and thus embody disaffiliation with, addressees, showing how speakers withhold or delay doing this action - thereby treating it as dispreferred.

\section{Preference for Other-Praise over Self-Praise (the Preference to Avoid Self-Praise)}

In a relationship that is clearly complementary to the above-mentioned preference for self-criticism over other-criticism, if praise of a person is to be articulated, participants treat the action of other-praising as preferred over self-praising.

Praising another person - for example, when a speaker delivers an utterance that compliments, appreciates, credits, or congratulates an addressed-recipient - is a social action widely regarded as supporting social solidarity by satisfying involved participants' positive "face wants" - the desire to be approved of and liked (Brown \& Levinson, 1987:13). In contrast, self-praising - for example, when a speaker delivers an 
utterance that positively assesses him/herself or acclaims her/his own accomplishments - is a social action widely regarded as undermining solidarity, since "a raising of the self may imply a lowering of the other" (Brown \& Levinson, 1987:39). As mentioned earlier, Pomerantz (1978b) observes that, when people respond to compliments, there is a preference to avoid self-praise - compliment recipients should not agree with the compliment.

Extending Pomerantz's (1978b) findings, Pillet-Shore (2005; 2012a) demonstrates that the social action of complimenting can be done not only by directly positively assessing some aspect of one's addressed-recipient, but also by praising a specific referent for which one's addressed-recipient is regarded as responsible. For example, during parent-teacher conferences, participants treat teachers' praise of focal nonpresent students as tantamount to compliments of parents, and likewise treat parents' praise of their own children as tantamount to self-praise (Pillet-Shore, 2012a).

When teachers praise nonpresent students, they recurrently produce a positivelyvalenced assessment of the student's academic performance and/or in-class behavior (e.g., "He's doin' really well"; "Academically she's wonderful"). And teachers produce their student-praising utterances with preferred design features - fluently, straightforwardly (without delay, qualification/mitigation, or account) and with an active grammatical construction that incorporates explicit reference to the student (PilletShore, 2012a; 2016). In contrast, parents treat their articulation of student-praising utterances as structurally dispreferred: they observably work to avoid praising students when interacting with teachers. And when they do deliver an utterance that reflects favorably on the student, that utterance: (i) usually does not directly assess the 
student's academic achievement or behavior, but rather merely mentions a favorable fact about the student (e.g., "Jason has like a 4.0 GPA"); and (ii) is delayed, qualified, and/or accounted for (Pillet-Shore, 2012a:183). In addition, parents respond to teachers' student-praising utterances in ways that avoid saying anything semantically fitted to the specifics of the teacher's prior turn (e.g., by producing laugh tokens, continuers, allowing silence to develop, or delivering sequence-closing acknowledgement tokens), thereby avoiding agreement (Pillet-Shore, 2012a).

Thus, the preference for teachers to praise students, and for parents to avoid praising their own children, seems to be a specific manifestation of the more general preference for the person least/not responsible for a positively-valued referent to be first to call attention to it. ${ }^{7}$ Much as it is better for the maintenance of "face" (Goffman, 1967) and social solidarity if a dinner guest is first to comment upon the fact that the main course is delicious, it is likewise better for the maintenance of all involved parentteacher conference participants' "face" if the teacher is first to comment upon the student's successes, thereby enabling the parent(s) to avoid implications of self-praise (Pillet-Shore, 2012a).

\section{FUTURE DIRECTIONS}

As the preceding overview of classic and contemporary CA research in this area attests, preference is a compelling and fertile domain of inquiry capable of producing

\footnotetext{
7 Here I am adapting Schegloff's (2007: 82) observation that, "In achieving the official and explicit registering of some feature of the environment of the interaction affiliated to or identified with one of the participants - and "positively valued" features in particular - there appears to be a preference for noticingby-others over announcement-by-"self" (where "self" is the one characterized by the feature.)" Because Schegloff notes that at the time of his writing he had "no taped instances [of this phenomenon] at hand" (2007: 86-87), see Pillet-Shore $(2005 ; 2008)$ for analyses of recorded instances of registering sequences.
} 
powerful insights about human sociality. To continue developing and refining our understanding of preference organization, the following questions could serve as potential foci for future investigations:

- When do participants produce dispreferred actions with preferred design features? The preference literature implies the existence of a preference matrix containing both congruent and incongruent possibilities: congruence occurs when a person produces a preferred action with preferred design features, or a dispreferred action with dispreferred design features; and incongruence occurs when a person produces a preferred action with dispreferred design features, or a dispreferred action with preferred design features. For example, Excerpts 17 and 18 show recipients of polar questions performing dispreferred responding actions in the preferred design format:

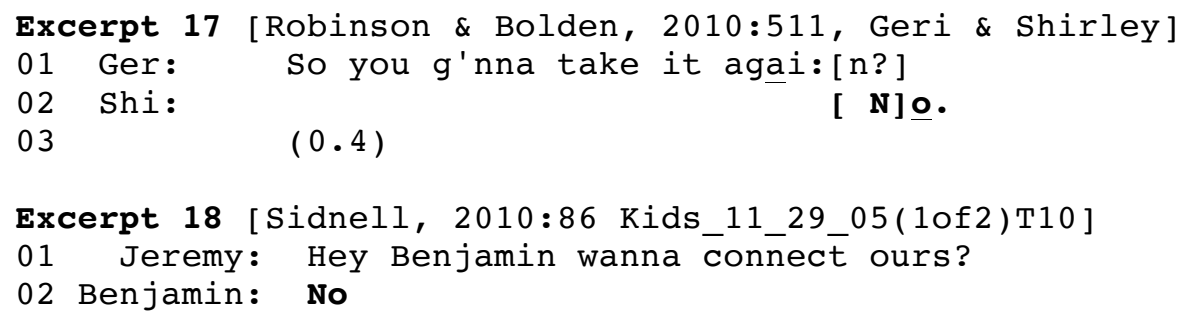

What accounts for such incongruence? Is it possible, for example, that adults regularly deliver dispreferred actions with preferred design features as a method of performing social closeness/intimacy? Or that children (e.g., aged 5-10 years) deliver dispreferred actions (e.g., other-corrections) with preferred design features when interacting with peers and/or adults?

- How well does our current understanding of preference organization apply to interactions among participants in various age and cultural groups? 
- How might the number of participants involved in an interaction impact the preference organization of certain social actions?

- Are preference organization findings based upon examinations of casual, ordinary conversations applicable to various forms of institutional interaction?

- When do participants' most salient situated identities observably impact how they design their talk and whether their talk is perceived as dis/preferred?

Preference organization research is poised to answer these and many other exciting questions as it continues to illuminate the orderliness of everyday human social interaction.

\section{Further Reading}

Heritage, J. (1984). Garfinkel and ethnomethodology. Cambridge: Polity Press. Pomerantz, A. \& Heritage, J. (2013). Preference. Pp. 210-228 in J. Sidnell \& T. Stivers (Eds.), The handbook of conversation analysis. Blackwell Publishing Ltd.

Schegloff, E. A. (2007). Sequence Organization in Interaction: A Primer in Conversation Analysis, (Vol. 1). Cambridge, UK: Cambridge University Press. 


\section{References}

Bolden, G. \& Robinson, J. (2011). Soliciting accounts with why-interrogatives in conversation. Journal of Communication, 61(1): 94-119.

Boyd, E., \& Heritage, J. (2006). Taking the patient's medical history: Questioning during comprehensive history taking. Pp. 151-184 in J. Heritage \& D. W. Maynard (Eds.), Communication in medical care. Cambridge, UK: Cambridge University Press.

Brown, P. \& Levinson, S. C. (1987). Politeness: Some universals in language usage. Cambridge, UK: Cambridge University Press.

Clayman, S. E. (1993). Reformulating the question: A device for answering/not answering questions in news interviews and press conferences. Text, 13(2): 15988.

Clayman, S. E. (2001). Answers and evasions. Language in Society, 30:403-42.

Drake, V. (2013). Turn-final or in English: A conversation analytic perspective. Unpublished Ph.D. dissertation. Department of English Language and Linguistics, University of Wisconsin, Madison.

Drew, P. (1992). Contested evidence in a courtroom cross-examination: The case of a trial for rape. Pp. 470-520 in P. Drew \& J. Heritage (Eds.), Talk at work: Interaction in institutional settings. Cambridge: Cambridge University Press.

Enfield, N. J. (2013). Reference in conversation. Pp. 433-454 in J. Sidnell \& T. Stivers (Eds.), The handbook of conversation analysis. Blackwell Publishing Ltd.

Goffman, E. (1967). Interaction ritual: Essays in face to face behavior. Garden City, NY: Doubleday. 
Goodwin, C. (1979). The interactive construction of a sentence in natural conversation. Pp. 97-121 in G. Psathas (Ed.), Everyday language: Studies in ethnomethodology. New York: Irvington.

Goodwin, M. H. \& Goodwin, C. (1986). Gesture and coparticipation in the activity of searching for a word. Semiotica, 62(1/2):51-75.

Heritage, J. (1984). Garfinkel and ethnomethodology. Cambridge: Polity Press.

Heritage, J. \& Sefi, S. (1992). Dilemmas of advice: Aspects of the delivery and reception of advice in interactions between health visitors and first time mothers. Pp. 359417 in P. Drew \& J. Heritage (Eds.), Talk at work: Interaction in institutional settings. Cambridge: Cambridge University Press.

Jefferson, G. (1978). Sequential aspects of storytelling in conversation. Chapter 9 in J. Schenkein (Ed.), Studies in the organization of conversational interaction. New York, NY: Academic Press.

Kendrick, K. \& Drew, P. (2014). The putative preference for offers over requests. Pp. 87-113 in P. Drew \& E. Couper-Kuhlen (eds.), Requesting in social interaction. John Benjamins.

Kendrick, K. \& Torreira, F. (2015). The timing and construction of preference: A quantitative study. Discourse Processes, 52(4), 255-289.

Lerner, G. H. (1996). Finding "face" in the preference structures of talk-in-interaction. Social Psychology Quarterly, 59(4), 303-321.

Lindstrom, A. \& Sorjonen, M. (2013). Affiliation in conversation. Pp.350-369 in J. Sidnell \& T. Stivers (Eds.), The handbook of conversation analysis. Blackwell Publishing Ltd. 
Nishizaka, A. \& Hayano, K. (2015). Conversational preference. In K. Tracy (General Editor), C. Ilie \& T. Sandel (Associate Editors), The International Encyclopedia of Language and Social Interaction, First Edition. John Wiley \& Sons, Inc.

Pillet-Shore, D. (2005). Calling attention to mutually-perceivable referents: How registering works when opening face-to-face interaction. Unpublished manuscript. Department of Sociology, University of California, Los Angeles.

Pillet-Shore, D. (2008). Coming together: Creating and maintaining social relationships through the openings of face-to-face interactions. Unpublished Ph.D. dissertation. Department of Sociology, University of California, Los Angeles.

Pillet-Shore, D. (2010). Making way and making sense: Including newcomers in interaction. Social Psychology Quarterly, 73(2), 152-175.

Pillet-Shore, D. (2011). Doing introductions: The work involved in meeting someone new. Communication Monographs, 78(1), 73-95.

Pillet-Shore, D. (2012a). The problems with praise in parent-teacher interaction. Communication Monographs, 79(2), 181-204.

Pillet-Shore, D. (2012b). Greeting: Displaying stance through prosodic recipient design. Research on Language and Social Interaction, 45(4), 375-398.

Pillet-Shore, D. (2015a). Being a "good parent" in parent-teacher conferences. Journal of Communication, 65(2), 373-395.

Pillet-Shore, D. (2015b). Compliments. In K. Tracy (General Editor), C. Ilie \& T. Sandel (Associate Editors), The International Encyclopedia of Language and Social Interaction, First Edition. John Wiley \& Sons, Inc.

Pillet-Shore, D. (2016). Criticizing another's child: How teachers evaluate students 
during parent-teacher conferences. Language in Society, 45(1), 33-58.

Pomerantz, A. (1978a). Attributions of responsibility: Blamings. Sociology, 12, 115-21.

Pomerantz, A. (1978b). Compliment responses: Notes on the co-operation of multiple constraints. In J. Schenkein (Ed.), Studies in the organization of conversational interaction (pp. 79-112). New York, NY: Academic Press.

Pomerantz, A. (1984). Agreeing and disagreeing with assessments: Some features of preferred/dispreferred turn shapes. In J. M. Atkinson \& J. C. Heritage (Eds.), Structures of social action (pp. 57-101). Cambridge, UK: Cambridge University Press.

Pomerantz, A. \& Heritage, J. (2013). Preference. Pp. 210-228 in J. Sidnell \& T. Stivers (Eds.), The handbook of conversation analysis. Blackwell Publishing Ltd.

Raymond, G. (2003). Grammar and social organization: Yes/no interrogatives and the structure of responding. American Sociological Review, 68, 939-967.

Robinson, J. \& Bolden, G. (2010). Preference organization of sequence-initiating actions: The case of explicit account solicitations. Discourse Studies, 12(4): 501533.

Sacks, H. (1974). An analysis of the course of a joke's telling in conversation. Pp. 337353 in Explorations in the ethnography of speaking, R. Bauman \& J. Sherzer (Eds.). Cambridge: Cambridge University Press.

Sacks, H. (1987). On the preferences for agreement and contiguity in sequences in conversation. Chapter 2, pp. 54-69 in Talk and social organization, G. Button \& J. R. E. Lee (Eds.). Clevedon: Multilingual Matters.

Sacks, H. (1992). Lectures on conversation, Volumes I and II (Fall 1964-Spring 1972). 
Oxford, Blackwell.

Sacks, H. \& Schegloff, E. A. (1979). Two preferences in the organization of reference to persons and their interaction. Pp.15-21 in G. Psathas (Ed.), Everyday language: Studies in ethnomethodology. New York: Irvington.

Sacks, H., Schegloff, E. A., \& Jefferson, G. (1974). A simplest systematics for the organization of turn-taking for conversation. Language, 50(4), 696-735.

Schegloff, E. A. (1972). Notes on a conversational practice: Formulating place. Pp. 75119 in D. Sudnow (Ed.), Studies in social interaction. New York: Free Press.

Schegloff, E. A. (1979). Identification and recognition in telephone openings. Pp. 23-78 in G. Psathas (ed.), Everyday language; Studies in ethnomethodology. New York: Erlbaum.

Schegloff, E. A. (1996). Some practices for referring to persons in talk-in-interaction: A partial sketch of a systematics. Pp. 437-485 in B. Fox (Ed.), Studies in anaphora. Amsterdam, John Benjamins.

Schegloff, E. A. (2007). Sequence Organization in Interaction: A Primer in Conversation Analysis, (Vol. 1). Cambridge, UK: Cambridge University Press.

Schegloff, E. A. \& Lerner, G. H. (2009). Beginning to respond: Well-prefaced responses to Wh-questions. Research on Language and Social Interaction, 42:2, 91-115.

Schegloff, E. A., \& Sacks, H. (1973). Opening up closings. Semiotica, 8, 289-327.

Schegloff, E. A., Jefferson, G. \& Sacks, H. (1977). The preference for self-correction in the organization of repair in conversation. Language, 53(2), 361-82. doi: http://dx.doi.org/10.2307/413107

Sidnell, J. (2010). Conversation analysis: An introduction. Wiley-Blackwell. 
Stivers, T., Enfield, N. J. \& Levinson, S. C. (2007). Person reference in interaction. Pp. 1-20 in N. J. Enfield \& T. Stivers (Eds.), Person reference in interaction: Linguistic, cultural, and social perspectives. Cambridge: Cambridge University Press.

Stivers, T. \& Robinson, J. (2006). A preference for progressivity in interaction. Language in Society, 35, 367-392.

Stivers, T. (2008). Stance, alignment, and affiliation during storytelling: When nodding is a token of affiliation. Research on Language and Social Interaction, 41(1), 31-57.

Stivers, T., Enfield, N. J., Brown, P., Englert, C., Hayashi, M., Heinemann, T., Hoymann, G., Rossano, F., de Ruiter, J.P., Yoon, K, Levinson, S C. (2009). Universality and cultural specificity in turn-taking in conversation. Proceedings of the National Academy of Science, 106, 10587-10592. 


\section{Appendix: Transcript Notation Conventions}

\begin{tabular}{|c|c|}
\hline A : & Speaker identification \\
\hline [ & Onset of overlapping talk \\
\hline$=$ & Utterances that are latched together, with no gap of silence between them \\
\hline- & The sound preceding the hyphen is cut off \\
\hline _: & The pitch turns downward within the word \\
\hline$\overline{:}$ & The pitch turns upward within the word \\
\hline$(0.4)$ & Timed silence measured in seconds and tenths of seconds \\
\hline$(\cdot)$ & A micropause of less than 0.2 -second \\
\hline : & The preceding sound is stretched \\
\hline • & Falling intonation \\
\hline , & Continuing or slightly rising intonation \\
\hline ? & Rising intonation \\
\hline$\dot{\imath}$ & Intonation between continuing and rising \\
\hline messy & Underlining: Emphasis or increased volume relative to surrounding talk \\
\hline$\overline{{ }^{\circ} \mathrm{I}}$ dunno ${ }^{\circ}$ & Degree signs: Decreased volume relative to surrounding talk \\
\hline$!$ & The preceding sound is abruptly punctuated \\
\hline$\uparrow \downarrow$ & Up or down arrow: A sharp rise or fall in pitch \\
\hline$>$ fast $<$ & Greater-than/less-than signs: Increased pace of talk relative to surrounding talk \\
\hline$<$ slow $>$ & Less-than/greater-than signs: Decreased pace of talk relative to surrounding talk \\
\hline \# & Scratchy voice \\
\hline$£$ & Smile voice \\
\hline$\sim$ & Shaky voice \\
\hline. $\mathrm{hh}$ & In-breath; the more ' $h$ 's the longer the in-breath \\
\hline $\mathrm{hh}$ & Out-breath (sometimes indicating laughter); the more ' $h$ 's the longer the out-breath \\
\hline hah hih & Beat(s) of laughter \\
\hline (doubt) & Filled single parentheses: Transcriber doubt about talk \\
\hline$(($ cough $))$ & Filled double parentheses: Scenic detail not easily transcribed \\
\hline * & Onset of visible conduct subsequently described inside double parentheses \\
\hline & Onset of second type of visible conduct within a single line of transcript \\
\hline bold & Targ \\
\hline
\end{tabular}

